\title{
The Application of Digital Technology in Ceramic Cultural Relics Restoration
}

\author{
Wang Yanni \\ Northwestern Polytechnical University \\ the School of Humanities Economy and Law \\ Xian city of Shanxi province China18792417767 \\ 610748445@qq.com
}

\author{
Zhang He \\ Northwestern Polytechnical University \\ the School of Humanities Economy and Law \\ Xian city of Shanxi province, China 18220818989 \\ 200838725@qq.com
}

\begin{abstract}
Digital technology has a significant advantage in the application of cultural relics protection and restoration. Based on the theoretical foundation, the thesis analyzed the utilization of modern digital simulation technology, and explored the improvement of ancient ceramics cultural relics restoration. Meanwhile, it revealed the potential applications of digital in ceramic artifacts protection and restoration of the study, which aimed to propose a solution in practice to face the problem for today's digital technology of ceramic artifacts simulation and restoration.
\end{abstract}

Keywords - Ceramic cultural relics; Digital; Restoration; Simulation

Cultural relics are the carriers throughout the ancient civilizations, the witness of China's five thousand years of human civilization and non renewable and irreplaceable of historical cultural heritage. Along with the age, cultural relics will be encountered the sun, weathering, soil burial, flooding, dehydration, corrosion damage, if not promptly repair and protect these cultural relics, they will become increasingly worse, and exquisite appearance and entity final demise with the passage of time.Once dusty thousand years of cultural relics were unearthed, how to repair, preservation, how to make more extensive geographical and more far-reaching people to eternal sharing these beautiful relics and appreciate the civilization behind, which is always a problem placed in the cultural workers and art researchers.

\section{THE PRESERVATION AND RESTORATION OF CULTURAL RELICS}

Cultural relic's restoration refers to the repair process of damaged cultural relics, which diseases can be eliminated, deterioration is under control and damage can be restored, no matter we use modern technology or traditional process, all of them are cultural relic's restoration. The discriminate of traditional repair techniques and modern protection technology are formed by history, China's cultural relics protection technology began with the traditional repair technique, each of the museum's cultural relic's protection start with system repair, then use the modern new technology. Therefore we used to call the traditional cultural relics' repair technology repair, and call the application of chemical and physical methods digital simulation, eliminating patients with control of a qualitative change in the technical work protection or maintenance. The direction of cultural relics work development should be both binding and fusion, rather than deliberately distinguish.

The complete traditional restoration mainly relys on the conservator's judgment and manual merging of incomplete relics and conservators need to have a lot of knowledge based on humanism, history, art and archaeology, at the same time they also need a high manual craft skill and experience. In recent years, besides the traditional repair and protection processes are inherited and carried forward, the extensive application of advanced science and modern information technology, which makes great progress in the unearthed relics protection, reinforcement, repair technology and by means of the advanced multimedia and virtual reality technology to make our country ancient cultural heritage digital display and effective protection. People could have permanent preservation of heritage information and reduce man-made damage to the heritage throughout the non-contact data acquisition and optical measurement techniques. If via the Internet, we could quickly achieve the resource sharing, and improve efficiency. Now cultural relic's protection repair gradually develops from the handicraft industry to an independent technical discipline and forms a complete system.

With in-depth development of the era of information and computer technology, especially the universal coverage of the network technology, digital storage and transmission technology, during working and living, people use the information processing, storage, inquiry more and more convenience, so it is on protection of cultural relics digitization. As an important adjunct to the study of cultural relics, the relics of digital protection technology not only record and store the information, but also supply people for study and appreciate according to the heritage material characteristics and using digital technology, 3D scanning, providing virtual cultural relics. People using the digital restoration technology not only is conducive to speed up the relic's recovery, but also preserves the heritage and develops a deeper level of cultural heritage, thus promoting the study of human cultural history and the history of social evolution. The most famous in abroad "Michelangelo Project" at Stanford University includes 10 sculptures digital, which the famous statue of David model including 200 million strips and 7000 colour photograph. The domestic cultural relics digital project mainly has: The digital imperial palace project was made by the Palace Museum in cooperation with Japan Toppan 
Printing Co. Ltd; The virtual tour of Dunhuang grottoes and mural restoration system developed by Zhejiang University; The " terracotta Museum No. two pits sites of 3D digital modeling project" was made by Qin Terracotta Army Museum in cooperation with Xi'an four-dimensional airborne survey for remote sensing center and so on.

\section{THE STUDY ON THE NECESSITY OF APPLICATION OF DIGITAL TECHNOLOGY IN CERAMIC RESTORATION}

Ceramics are a general term for pottery and porcelain; ceramic cultural relics have a special importance in heritage. The ceramics were unearthed in addition to the use in feed implement and adornment, also play an important role in science and development of technology. As one of Chinese culture of ceramic cultures it inoculated, grown and developed in the national matrix, and embodied the creators of emotion vividly, with the fragrance of the soil, and preserved the creator heart and hand corresponding of the artistic image. It is the performance of the national culture, narrative with a pleasant story, shows with broad social life picture, records with the mob joys and sorrows, descript with the nation's mental, spirit and character of development and change, with the nation's happiness and sadness on, so we can say that is a representative of the ceramic. It is a symbol of historical development, ceramic artifacts in the present domestic relics of the land, occupies a large number of the ratio, therefore, its protection and restoration are very important.

I choose from the ceramic artifacts of modern restoration technology to research, when I said the ceramic artifacts digital research, I can't help speaking of the virtual reality technology. Since the 1990s, virtual reality technology has been widespread concern in the scientific community, in recent years, with the rapid development of computer and network technology, it has made a great progress. In fact the virtual reality technology is using the multimedia computer technology to realize physical and realistic environment 2D even 3D simulation, also known as the reality of the virtual. In the construction of computer's virtual world, it will show the real world situation, and let people feel reality in never travel and never leave home conditions, which seems immersive general and even realize the user and the virtual environment directly interaction. The produce of virtual reality technology comes from the military training needs first, now it is widely used in the field of aerospace, aviation, marine, medical training, architecture and environmental planning and design, film and television production and cultural relics archaeological research etc.

Because of the virtual of only static forms of the ceramic cultural relic's virtual reality, it is more easily realized in the technology. At the same time, ceramic artifacts entities generally have bright color, different patterns of 3D shape characteristics, which is more conducive to play out of the great advantages of the virtual reality technology. Ceramic cultural relics digital virtual reproduction mainly has the application of following several aspects.

A Digital and virtual display of the ceramic cultural relics

Many ceramic cultural relics are only deep in the ground all the year round because of ceramic cultural relics being fragile easily and difficult to off-site exchange, more people's desire to see the countenance is difficult to achieve. Using virtual reality technology, people could display the digital of ceramic cultural relics and bring many difficult to contact and a rare ceramic relics treasures all over the world easy here together, let the people around the world enjoy together without the limitation of time and space, which has a positive effect to ceramic heritage protection, research and knowledge dissemination. The digital display has greatly extended the number of times and quantity of ceramic cultural relics' exhibit, the audience can intimate contact with the heritage by screen display the virtual ceramic and be able to research the virtual image details of amplifying appreciation. Decomposition of the ceramic structure, clear perspective, close observation and experience its color, texture and other elements, not only interprets the connotation of cultural relics better, the viewer observed more thorough, but also makes the audience have a more keen interest in cultural relics, expanding science propaganda, and enhance the publicity effect, enrich the significance of the exhibition in the vivid display, at the same time it was reached the purpose of protection.

In the repair process of ceramic cultural relics, the digital restore means effectively protect the cultural relics less subject to injury, the digital's 2D and 3D simulation of repair technology makes artifacts to non contact restoration and display, which effectively protects the cultural relics' original, at the same time the digital information of cultural heritage has been permanently saved. From the very beginning, digital image processing technology and virtual reality technology is only technical aspects as secondary relic's recovery in the process of repair of cultural relics, used to simulate the recovery and testing, this technique is applied to the show, and it reflects the full range of protection for cultural relics, its role is unprecedented. The digital technique to repair cultural relics is the main use of the intelligent editor of digital 2D images and 3D virtual technology. The digital 2D image protection and restoration of image information can be permanent preserved and use digital technology to virtual restoration of the screen. To collect and arrange the digital information and picture data, it can be used in drawing Adobe Photoshop, Illustrator, Freehand software. The application of virtual reality technology in the repair of 3D simulation greatly improves the efficiency of protection of cultural relics. Virtual Reality also translated the temporary environment, spirit and environment, etc, From the application point of view, it is an integrated computer graphics technology, multimedia technology, human-computer interaction technology, network technology, three-dimensional display technology and simulation technology, a variety of science and technology development up on the latest technology of computer, also the comprehensive application of mechanics, mathematics, optics, kinematics, and other disciplines. The characteristics of the field of computer technology is to mimic the way for the user to create a virtual environment, it allows users to generate the feel of an immersive virtual environment through vision, hearing, touch perception behavior, and interaction with the virtual environment in order to cause the virtual environment changes in real-time. 

relics

Digital repair and restore of the ceramic cultural

In ceramic archaeological research, repair and restore many rare but defect of ceramic artifacts, has been occupied an important position. For many years ceramic archaeologists unearthed a number of extremely valuables but it is the defect of ceramic artifacts, once upon a time, people usually use traditional craft to repair the broken ceramic artifacts, they often produced a large number of experiments and test products, but also may not be able to get good repair and reduction effect. With digital virtual reality technology, people can easily make, modify and repair the true colors of the ceramic artifacts reduction defects in a virtual world of computer, in order to achieve the best artistic effect. This point in time the physical production experiments will achieve a multiplier effect. This virtual reproduction technology also brings a number of ceramic artifacts expert research results together through the network, gambling house director of public, synthesis produced by digital technology to achieve the best results, which can be shared on the network so that more ordinary people can participate in researching and sharing of digital research.

C Digital reproduction and development of the lost ceramic cultural relics

In the ceramic archaeology research, reproduce many ceramic arts that lost in the world is also an important research topic. If the repair defects of cultural relics can be speculated through surviving physical residue of modeling, then in historical record has no physical works of ceramic art needed to infer from the imagination, and virtual reality technology can make this kind of imagination to get the maximum play. At the same time people can also have virtual development of ceramic works in the design impression and digital design, when come to a satisfactory shape color effect, collect scientific data characteristics, then do the physical production, which will greatly improve the success rate of the ceramic works of repair and reproduce.

\section{PRESENT PROBLEMS AND MEASUREMENTS OF} DIGITAL TECHNOLOGY SIMULATION AND THE REPAIR OF THE CERAMIC CULTURAL RELICS

\section{A Ignorance of the establishment of the ceramic cultural relics restore files}

Conservation files are generated in the process of repair activities of cultural relics; it has an important conservation value, as the real history in accordance with the file system, and centralized custody up the restoration of cultural relics information. Their performances are text data, tables, pictures, photographs, film and video from. Conservation file is an important manifestation of heritage restoration work more scientific and standardized; however, today there are many problems in the ceramic artifacts to create a recovery file, not only exist on the records of the content missing and various forms files of quality does not meet requirements, but the file record formats and record carrier has a defect of the type single. The use of modern means of science and technology can effectively increase the scientific and precision of conservation file creation; it requires government departments to give a proper policy support, increased capital investment and to improve the previous antiquated archive storage.

$B$ The lack of domestic technicians mastering ceramic cultural relics digital simulation and repair

According to my survey, only a handful of museum technicians in nationwide can repair the ceramic cultural relics of modern digital technology; this does not meet the need of repair and protection work of ceramic cultural relics. From the professionals reserves and education, many universities and research institutions are not set such a professional. Simulation and repair of digital technology on ceramic artifacts belonging to the cross-disciplinary professional computer and conservation, this cross-disciplinary often as interdisciplinary treatment, it is difficult to obtain strong support for personnel training and technical facilities, this situation is not conducive to the simulation of digital technology on ceramic artifacts and repair. To resolve this problem, we should attention and implementation from the height of the protection of cultural relics and historical cultural, increase efforts to train specialized personnel, set up specialized courses in professional institutions and to organize various types of training courses. At the same time also require to the existing heritage conservation workers fully understand the heritage value, the right to develop protection and restoration measures, in order to obtain the success of cultural relics conservation.

C The potential risks of intellectual property on the technology of domestic ceramic cultural relics' protection and restoration

China is a country with the most unearthed ceramic cultural relics, it has potential for the formation of independent intellectual property rights in the preservation and restoration of technology innovation. This modern technology patent and copyright protection should be included in the scope of legal protection in China; however, according to my survey, our country has not yet formed a system of legal protection of cultural relics. This situation sets the potential problems for our simulation technology innovation, prevention and resolution of such problems requiring the departments to enhance the "System first, Legal defense" consciousness, and do more useful system of reserves and improve measures for the application of digital technology in ceramic conservation escort.

\section{REFERENCES}

[1] Bai Ming. An Overview of World Modern Ceramics[M]. Jiangxi Art Publishing House, 1999.

[2] ZhangYao, Zhou Yijun. A Study on Modern Ceramics[M]. Jiangxi Art Publishing House, 2006.

[3] Wu Yuhan, Zhou Mingquan. Application of Three Dimensional Scanning Technology in The Conservation of Cultural Relics[J].Computer Technology And Development, 2009.

[4] A Preliminary Study on The Digitization of Historical Materials. http://jgw.ayinfo.ha.cn/ archives/000008.html

[5] The Digital Cultural Relics And Art. http://nmlab.zju.edu.cn/sc/ research/sw.html 